\title{
Mating vibrational signal transmission through and between plants of an agricultural pest, the Glassy-Winged Sharpshooter
}

Shira Gordon; Ben Tiller; James Windmill; Peter Narins; Rodrigo Krugner

The agricultural pest, glassy-winged sharpshooter (GWSS), Homalodisca vitripennis, relies primarily on successful vibrational communication across its home plant. Males and females engage in a vibrational duet to identify correct species, attractiveness of mate, and location on the plant. The signal produced by these animals has a dominant frequency component between 80 and $120 \mathrm{~Hz}$, with harmonics spaced approximately $100 \mathrm{~Hz}$ apart. However, our analysis revealed that not all harmonics are present in every recorded signal. Therefore, we sought to understand how the GWSS vibrational communication signal changes over distance on the plant. We have confirmed that first, with increasing distance fewer high frequency harmonics are present. Second, at distances of only $50 \mathrm{~cm}$, there is a difference in the latency of signal arrival based on the frequency, with higher frequencies arriving sooner. Finally, the animal appears to generate no airborne signal component, yet, the low frequencies are clearly detectable in neighboring plants by the signal "jumping" from leaf-to-air-to-leaf. Together, these results highlight the complexity of vibration transmission in plants and the possibility of alteration and disruption of the GWSS signal.

Accepted manuscript of the following research output: Gordon, S., Tiller, B., Windmill, J., Narins, P., \& Krugner, R. (2018). Mating vibrational signal transmission through and between plants of an agricultural pest, the Glassy-Winged Sharpshooter. Journal of the Acoustical Society of America, 143(3), [1796]. 